\title{
Performance Appraisal System for Intern doctors in Selected Medical college hospitals of Bangladesh Current situation
}

\author{
Dr. Riffat Rahim ${ }^{\prime}$, Professor Dr. Iffat Ara ${ }^{2}$, Professor Dr. Md Humayun Kabir Talukder ${ }^{3}$, Dr. Kazi Khairul Alam ${ }^{4}$
}

\begin{abstract}
Background: Formal assessment could ensure all junior doctors receive feedback about their performance in the workplace early in their career, essential for professional development.

Aim: . This study was aimed to analyze the situation of performance appraisal system of intern doctors in different medical college hospitals of Bangladesh.

Method: This descriptive, cross-sectional study was carried out at 9 medical college hospitals( 4 govt. and 5 non govt.) for a period of one year(July2016-June 2017) among 52 teachers and 445 intern doctors. Convenience sampling technique was administered. Data were collected by using self administered semi structured questionnaire. Data analysis were done using SPSS version 19.0 software.

Results: The study revealed that the medical college hospitals under this study had mostly satisfactory internship training facilities. About $56 \%$ interns responded negatively about the utilization of logbook in each major discipline rotation. Around $54 \%$ of them responded negatively about the practice of performance appraisal system in their institute About $42.3 \%$ of teachers were not satisfied with the current practice of performance appraisal system of interns in their institute. However $27.5 \%$ teachers said that they arranged assessment always and $27.5 \%$ said that most of the time they arranged assessment for interns. About $35.5 \%$ interns blamed lack of interest of teachers about assessment of interns but $40 \%$ of teachers said work overload is the most important among the barriers in implementing appraisal system for interns. Around $42.1 \%$ interns suggested that existing logbook should be properly used and $48.9 \%$ of them suggested that the entire training should be under close supervision of the supervisors. Majority of the teachers were in favor of assessing interns on regular work along with formal assessment, they suggested regular morning session, ward round and bedside teaching should be ensured for the improvement of the standard of training.
\end{abstract}

Conclusions: Proper utilization of logbook, successful implementation of performance appraisal system with feedback, active monitoring committee for the interns were recommended by the study.

Key Words: Performance Appraisal System, Bangladesh Current situation

\section{Introduction}

Assessment and evaluation are crucial steps in educational process that play major role in the process of medical education, in the lives of medical students, and in society by certifying competent physicians who are able to take care of the public. (Tabish,2010).Most commonly, interns work as part of multidisciplinary team where the interns is the most junior doctor of a hospital. During this time, the intern will learn to make clinical decisions in a supervised environment and have direct responsibility being monitored and graded

\footnotetext{
${ }^{1}$ Consultant (Gynae \& Obs), Raiway general hospital, Dhaka

${ }^{2}$ Professor Dr. Iffat Ara, Professor of Obstetrics and gynaecology, Popular medical college, Dhaka,

${ }^{3}$ Professor, Curriculum Development \& Evaluation, Centre for Medical Education, Mohakhali, Dhaka

${ }^{4}$ Assistant Professor, Centre for Medical Education, Mohakhali, Dhaka
}

Address of correspondence: Dr. Rifat Rahim

Consultant (Gynae \& Obs), Raiway general hospital, Dhaka

E-mail: riffatrahim@yahoo.com according to their level of experience (Medical Council of Ireland, 2012).Internship training is a pre-requisite for $\mathrm{BM} \& \mathrm{DC}$ registration. It is desired that this training will make the interns equipped to serve people with safe and good quality patient care. At the end of the training their clinical performance should be assessed properly to get competent physicians who will be able to provide safe health care to the community. The internship training period is the vital time for the newly graduated doctors to attain the clinical competencies essential for their career. It is the opportunity to apply, consolidate and expand one's clinical knowledge and skills, and progressively increase one's responsibility for providing safe patient care. Performance appraisal is an essential system to assess the achievement of clinical competencies by the intern doctors. In the undergraduate setting, the ideal logbook is a tool that guides medical students through their clinical rotation by highlighting important clinical objectives, promoting self-reflection and providing opportunity to obtain feedback from preceptors. Intern doctors are the product of our MBBS curriculum. The study is designed to identify the current practice of assessment system for intern doctors in medical college hospitals of Bangladesh and to evaluate the extent of use of

Bangladesh Journal of Medical Education 2018;9(1):14-17. (C) 2018 Rahim et al., publisher and licensee Association for Medical Education. This is an Open Access article which permits unrestricted non-commercial use, provided the original work is properly cited. 
logbook by the interns. The intention of doing the study is to find ways and means for better implementation and further improvement of the system.

\section{Methodology}

The study was a descriptive type of cross-sectional study. It was carried out at 9 medical college hospitals( 4 govt. and 5 non govt.) for a period of one year(July2016-June 2017) among 52 teachers and 445 intern doctors of selected medical college hospitals. Out of total 9 medical colleges hospitals one government and one non government medical college hospitals were from out side Dhaka city and the rest were from Dhaka City. Convenience sampling technique was used for the study. The available and willingly participating intern doctors who completed at least one major department either Medicine or Surgery or Obstetrics \& gynaecology of the selected medical colleges hospitals of Bangladesh and available and willingly participating teachers who facilitated internship training program of selected medical colleges hospital of Bangladesh were included in the study. Participants who were unwilling to participate in the study or not available during the data collection period and foreigner intern doctors were excluded from the study. Data were collected by using self administered semi structured questionnaire from intern doctors \& teachers. After collecting responses, data were checked randomly for inconsistent and missing data to reduce errors. Collected data were analyzed and represented through the use of SPSS v 19.0 software.

\section{Results}

A five point Likert scale was used in the questionnaire were $* \mathrm{SDA}=$ Strongly Disagree $=1, \mathrm{DA}=$ Disagree $=2$, $\mathrm{NAND}=$ Neither agree nor disagree $=3, \mathrm{~A}=$ Agree $=4, \mathrm{SA}=$ Strongly Agree $=5$ were depicted to express the extent of agreement and disagreement. For each variable frequency distribution was calculated. Mean were also calculated in some cases.

Interpretation of the mean score was as follows:

$5=$ No need of further improvement, as it has reached a good standard

4 to $<5=$ Very minimum efforts are needed to reach a good standard

3 to $<4=$ Some efforts are needed to reach a good standard

2 to $<3=$ Moderate efforts are needed to reach a good standard

1 to $<2=$ Considerable efforts are needed to reach a good standard

Table 1: Distribution of interns response regarding use of logbook

\begin{tabular}{|c|c|c|c|c|c|c|c|}
\hline \multirow{2}{*}{ Statements in relation to interns responses } & \multicolumn{5}{|c|}{$\begin{array}{c}\text { Extent of agreement and disagreement } \\
\text { frequency }(\%)\end{array}$} & \multirow{2}{*}{ Total } & \multirow{2}{*}{$\begin{array}{l}\text { Mean } \\
( \pm \text { SD })\end{array}$} \\
\hline & SDA & DA & NAND & A & SA & & \\
\hline Logbook is useful as a guide for training & $31(7 \%)$ & $29(6.6 \%)$ & $55(12.5 \%)$ & $207(46.9 \%)$ & $119(27 \%)$ & 441 & $\begin{array}{l}3.80 \\
1.120\end{array}$ \\
\hline Filled up honestly & $40(9.1 \%)$ & $64(14.6 \%)$ & $51(11.6 \%)$ & $168(38.3 \%)$ & $116(26.4 \%)$ & 439 & $\begin{array}{c}3.58 \\
1.270\end{array}$ \\
\hline $\begin{array}{l}\text { Filled up at the end of each rotation, just to } \\
\text { take a signature }\end{array}$ & $69(15.6 \%)$ & $61(13.8 \%)$ & $51(11.5 \%)$ & $190(43 \%)$ & $71(16.1 \%)$ & 442 & $\begin{array}{c}3.30 \\
1.322\end{array}$ \\
\hline $\begin{array}{l}\text { Got feedback immediately after completion } \\
\text { of each component skill by the Supervisor }\end{array}$ & $39(8.9 \%)$ & $89(20.3 \%)$ & $84(19.1 \%)$ & $155(35.2 \%)$ & $73(16.6 \%)$ & 440 & $\begin{array}{c}3.30 \\
1.218\end{array}$ \\
\hline Used as document of achievement of training & $29(6.6 \%)$ & $61(13.9 \%)$ & $68(15.5 \%)$ & $21(48.1 \%)$ & $70(15.9 \%)$ & 439 & $\begin{array}{c}3.53 \\
1.116\end{array}$ \\
\hline
\end{tabular}

About $43 \%$ agreed that they filled up the logbook just to take a signature, however, 38.3\%agreed that they filled it up honestly but $48.1 \%$ agreed that logbook is used as document of achievement of training.

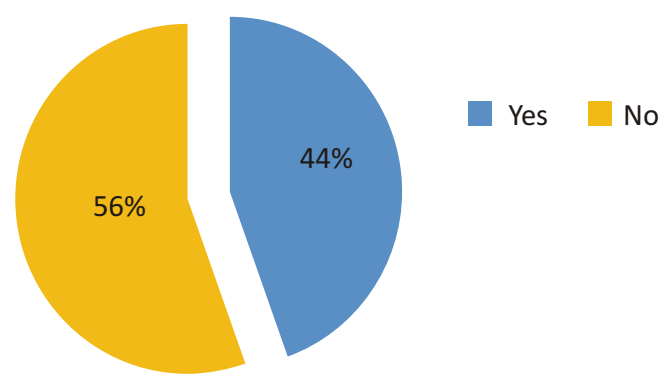

Figure 1: Interns response about the utilization of logbook in each major (Medicine, Surgery, Obs\& Gynae) discipline rotation

Bangladesh Journal of Medical Education 2018;9(1):14-17. 
About $43 \%$ agreed that they filled up the logbook just to take a signature, however, $38.3 \%$ agreed that they filled it up honestly but $48.1 \%$ agreed that logbook is used as document of achievement of training.

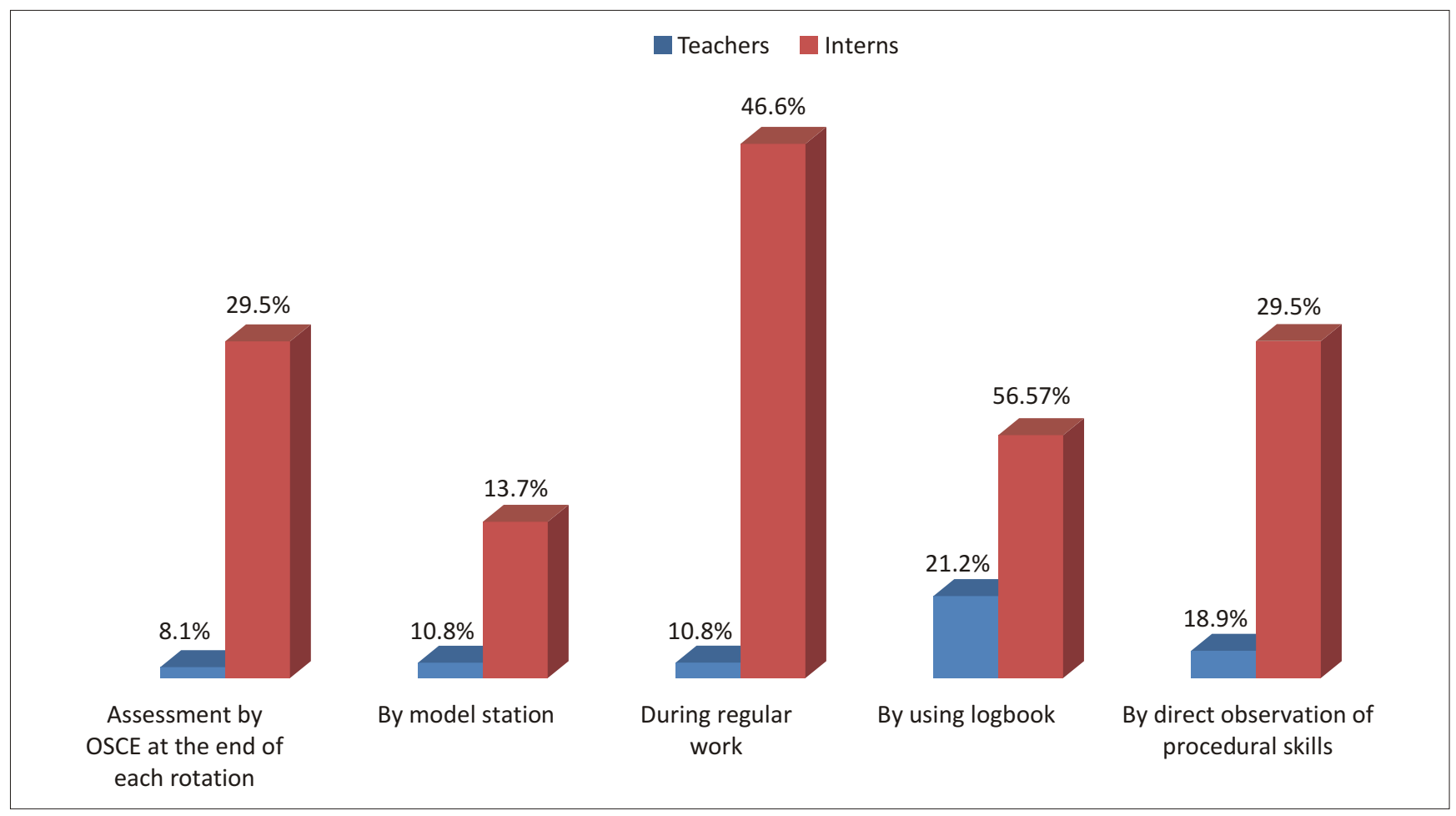

Figure 2: Responses of interns and teachers about assessment techniques practiced in their institutes.

Table 2: Distribution of Interns opinion about the barriers in implementing performance appraisal system in their institutes

\begin{tabular}{|l|c|c|}
\hline $\begin{array}{l}\text { The barriers in implementing } \\
\text { performance appraisal system in } \\
\text { their institute }\end{array}$ & Frequency & Percent \\
\hline Shortage of clinical teachers & 53 & 17.9 \\
\hline $\begin{array}{l}\text { Lack of interest of teachers about } \\
\text { assessment of interns }\end{array}$ & 105 & 35.5 \\
\hline Time constrains & 54 & 18.2 \\
\hline Work load of the supervisor & 34 & 11.5 \\
\hline Administrative problem & 45 & 15.2 \\
\hline Lack of interest of inters for assessment & 5 & 1.0 \\
\hline Total & 296 & 100.0 \\
\hline
\end{tabular}

Table 3: Distribution of teachers response regarding barriers of implementing appraisal system for interns

\begin{tabular}{|l|c|c|}
\hline $\begin{array}{l}\text { Barriers of implementing appraisal } \\
\text { system for interns }\end{array}$ & Frequency & Percent \\
\hline Lack of manpower & 4 & 16 \\
\hline Work overload & 10 & 40 \\
\hline Time constrains & 2 & 8 \\
\hline $\begin{array}{l}\text { Lack of interest of teachers for } \\
\text { performance assessment of interns }\end{array}$ & 7 & 28 \\
\hline $\begin{array}{l}\text { Lack of interest of interns for } \\
\text { assessment }\end{array}$ & 2 & 8 \\
\hline Total & 25 & 100 \\
\hline
\end{tabular}

About $35.5 \%$ interns blamed lack of interest of teachers about assessment of interns, however, about $40 \%$ teachers blamed work overload, is the most barrier in implementing performance appraisal system in their institute. About 32.6\% teachers were in favor of ensuring regular CME, training, morning session, ward round, bedside teaching as ways of improvement of assessment system. However, $33.5 \%$ interns suggested that entire training should be under close supervision to improve the assessment system, Both the teachers and interns gave emphasis on ensuring proper supervision of monitoring committee for internship training. Both the respondent groups thought that motivation of

Bangladesh Journal of Medical Education 2018;9(1):14-17. 
teachers and interns both is necessary to overcome the barriers. Sincerity and accountability towards own duties can bring the success.

\section{Discussion}

In this study, about $48.1 \%$ agreed that logbook is used as document of achievement of training. In another study done in King Abdul aziz University, Jeddah, Saudi Arabia, illustrated that $68.5 \%$ of respondents agreed that logbook is a useful assessment format.( Nahla Khamis Ibrahim, et al.2013).About $40.4 \%$ teachers thought that interns filled the logbook sincerely in each rotation of training but $48.1 \%$ teachers thought interns just only filled the logbook as pre requisite of training.Around $15.4 \%$ of them believed that interns only signed the logbook without supervision. The present study revealed, $54 \%$ of interns gave negative response about the practice of performance appraisal system in their institute. About $42.3 \%$ were not satisfied with the current practice of performance appraisal system in their institute. Interestingly interns and teachers differ significantly. About $46.6 \%$ interns stated that, they were assessed during regular work, whereas $10.8 \%$ teachers gave their opinion in favor of assessment during regular work. Around $56.7 \%$ teachers assessed their interns by using logbook, however, $21.2 \%$ interns told they were assessed by using logbook. About 29.5\% interns told that they were assessed by OSCE but $8.1 \%$ teachers told in favor of OSCE.

According to BM\&DC guideline, after completion of each component the interns have to appear assessment examination by OSCE and feedback will be given to interns. The assessment will be arranged by unit Head of the each component.(Bangladesh Medical and Dental Council,2002)

A study reported that the majority $(97.6 \%)$ of students believed that MCQ was frequently used method of evaluation in a clinical setting. OSCE (92.8\%) and logbook $(86.7 \%)$ were the next common methods. (Zadeh et al., 2012).

In this study, 35.5\% interns thought lack of interest of teachers about assessment of interns is the barrier in implementing performance appraisal system in their institute.However, $40 \%$ teachers blamed workload as a barrier in implementing performance appraisal system for interns in their institute.

The present study revealed, $42.1 \%$ interns thought, the existing logbook should be properly used, about $48.9 \%$ thought the entire training should be under close supervision of the supervisor for proper implementation of performance appraisal system in their institute Whereas, significant number of teachers suggested that ensuring regular morning session, ward round, bedside teaching and CME, assessment during regular work with immediate feedback and increasing the number of supervisor can be the initiatives to improve the performance appraisal system.

A study performed in UK revealed, one long-term solution for might be to incorporate 'training the trainers' into the curriculum, so that doctors in training are themselves learning to become the trainers of the future (Vassilas et al, 2003).

\section{Conclusion}

In the conducted study, majority of the interns and teachers responded negatively about the about the current practice of performance appraisal system in their institutes. There is a big gap between current practice of performance appraisal system and the system outlined in the logbook.

\section{Recommendation}

Proper utilization of logbook, successful implementation of performance appraisal system with feedback, active monitoring committee for the interns were recommended by the study. Further, extensive studies are required to overcome the barriers and proper implementation of performance appraisal system for intern doctors was also recommended.

\section{Acknowledgements}

Thankful to all the officers and staffs of CME,

\section{References}

1. Medical Council of Ireland, 2012 https:// en.m.wikipedia.org $>$ wiki.Media

2. Bangladesh Medical and Dental Council. 2012. 'BM\&DC Curriculums.' Retrieved August 2015, from BM\&DC:http//bmdc.org.bd/mbbs-curriculum-update2012

3. Christopher A. Vassilas,Nicholas Brown,David wall\& Hester Womersley;Advances in Psychiatric Treatment(2003),vol.9,308-315

3. Jalil Kuhpayeh Zadeh, Helen Dargahi, Jila Shajari, Rafei Ali, Mahsa Narenjiha, Soudabeh Afsharpour, Darioush Mehdivarzi Creative Education 2012. Vol.3, Special Issue, 946-950 Published Online October 2012 in SciRes (http://www.SciRP.org/journal/ce)

5. Nahla Khamis Ibrahim, Budoor Mohammed AlSharabi,Rasha Abdullah Al-Asiri, Najat Abdullah Alotaibi,WejdanIbrahimAl-Husaini,HussaAdel Al

6. Tabish, A. (2010). Assessment Methods in medical education. International Journal of Heaith Sciences, 2, 3-7.

Bangladesh Journal of Medical Education 2018;9(1):14-17. 